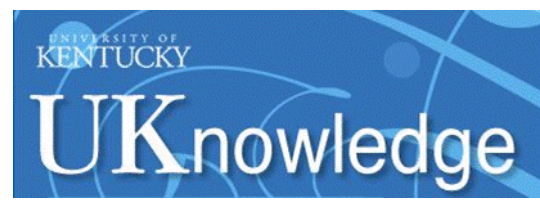

University of Kentucky

UKnowledge

\title{
Drinking to Distraction: Does Alcohol Increase Attentional Bias in Adults With ADHD?
}

\author{
Walter Roberts \\ University of Kentucky, walter.roberts@uky.edu \\ Mark T. Fillmore \\ University of Kentucky, fillmore@uky.edu \\ Richard Milich \\ University of Kentucky, richard.milich@uky.edu
}

Follow this and additional works at: https://uknowledge.uky.edu/psychology_facpub

Part of the Psychology Commons

Right click to open a feedback form in a new tab to let us know how this document benefits you.

\section{Repository Citation}

Roberts, Walter; Fillmore, Mark T.; and Milich, Richard, "Drinking to Distraction: Does Alcohol Increase Attentional Bias in Adults With ADHD?" (2012). Psychology Faculty Publications. 121.

https://uknowledge.uky.edu/psychology_facpub/121

This Article is brought to you for free and open access by the Psychology at UKnowledge. It has been accepted for inclusion in Psychology Faculty Publications by an authorized administrator of UKnowledge. For more information, please contact UKnowledge@lsv.uky.edu. 


\title{
Drinking to Distraction: Does Alcohol Increase Attentional Bias in Adults With
} ADHD?

\author{
Digital Object Identifier (DOI) \\ http://dx.doi.org/10.1037/a0026379

\section{Notes/Citation Information}

Roberts, W., Fillmore, M. T., \& Milich, R. (2012) Drinking to Distraction: Does Alcohol Increase Attentional Bias in Adults With ADHD?. Experimental and Clinical Psychopharmacology. 20, (2): 107-117.

Copyright (C) 2012 American Psychological Association.

This article may not exactly replicate the final version published in the APA journal. It is not the copy of record. 


\section{Experimental and Clinical Psychopharmacology}

\section{Drinking to Distraction: Does Alcohol Increase Attentional Bias in Adults With ADHD?}

Walter Roberts, Mark T. Fillmore, and Richard Milich

Online First Publication, November 28, 2011. doi: 10.1037/a0026379

CITATION

Roberts, W., Fillmore, M. T., \& Milich, R. (2011, November 28). Drinking to Distraction: Does Alcohol Increase Attentional Bias in Adults With ADHD?. Experimental and Clinical

Psychopharmacology. Advance online publication. doi: 10.1037/a0026379 


\title{
Drinking to Distraction: Does Alcohol Increase Attentional Bias in Adults With ADHD?
}

\author{
Walter Roberts, Mark T. Fillmore, and Richard Milich \\ University of Kentucky
}

\begin{abstract}
Previous research has shown that social drinkers continue to show attentional bias toward alcohol-related stimuli even after consuming a moderate dose of alcohol. In contrast, little is known about how alcohol acutely affects attentional bias in groups at risk to develop alcohol-related problems, such as adults with attentiondeficit/hyperactivity disorder (ADHD). Such individuals may show increased attentional bias following alcohol relative to nonclinical controls. The present study tested this hypothesis by examining acute alcohol effects on attentional bias in 20 social drinkers with ADHD and 20 social drinkers with no history of ADHD. Participants performed a visual-probe task after receiving the following doses of alcohol: $0.64 \mathrm{~g} / \mathrm{kg}, 0.32 \mathrm{~g} / \mathrm{kg}$, and $0.0 \mathrm{~g} / \mathrm{kg}$ (placebo). Those in the ADHD group showed increased attentional bias under active alcohol doses, whereas attentional bias was similar across doses in the control group. Attentional bias predicted ad libitum alcohol consumption during a taste-rating session. This relation was observed only in the ADHD group. These findings indicate that an acute alcohol dose increases attentional bias in adults with ADHD. Further, attentional bias appears to be a predictor of ad libitum consumption in this group.
\end{abstract}

Keywords: attentional bias, ADHD, alcohol, ad libitum consumption, at-risk drinkers

A large body of research has shown that substance users tend to allocate attention disproportionately toward substancerelated cues (Robbins \& Ehrman, 2004), and several models of substance abuse identify this tendency as central to continued substance use and relapse (Field \& Cox, 2008). These models describe attentional bias as resulting from conditioning processes by which substance-related cues obtain motivational salience and attract the attention of a substance user. Studies examining how alcohol acutely affects attentional bias have produced mixed results: some research suggests that attentional bias increases following alcohol (Duka \& Townshend, 2004; Schoenmakers, Wiers, \& Field, 2008), but other evidence suggests that attentional bias is unaffected by an alcohol dose (Miller \& Fillmore, 2011). Atypical subjective and behavioral responses to alcohol are known risk factors for later development of alcohol use disorders (Schuckit, 1994), and it may be that at-risk drinkers show atypical changes in attentional bias following alcohol. In the current study, we tested this notion by examining the effects of alcohol on attentional bias in a group of young adult drinkers who are at risk to develop alcohol-use problems (i.e., adults with ADHD).

Walter Roberts, Mark T. Fillmore, and Richard Milich, Department of Psychology, University of Kentucky.

This research was supported by the NIAAA Grants AA012895 and AA018274, and NIDA Grant DA005312. These funding agencies had no role in this research other than financial support. Each author contributed significantly to the preparation of this article. Each author has read and approved the final manuscript. The authors have no real or potential conflicts of interest to disclose.

Correspondence concerning this article should be addressed to Mark T. Fillmore, PhD, Professor, Department of Psychology, 115 Kastle Hall, Lexington, KY 40506-0044. E-mail: fillmore@uky.edu
Incentive theories of drug addiction acknowledged that substance-related cues acquire incentive-motivational properties. Repeated drug administration sensitizes dopamine pathways in brain regions associated with attribution of motivational salience. This process causes the substance to be perceived as "wanted," and the user becomes highly motivated to obtain and self-administer the substance (Field \& Cox, 2008; Robinson \& Berridge, 1993). This shift in motivational salience of substance-related cues causes attention to be biased in favor of these cues (Klinger \& Cox, 2004).

A variety of behavioral tasks are used to measure attentional bias toward substance-related cues (e.g., addiction-Stroop task, flicker-induced change blindness task; Cox, Fadardi, \& Pothos, 2006; Jones, Bruce, Livingstone, \& Reed, 2006). Arguably the most direct method of measuring attentional bias, however, is the visual-probe task. When performing this task participants view a pair of images presented side by side on a computer screen: one of these is a substance-related image, and the other is a neutral image closely matched to its substance-related counterpart. After a set delay, the images disappear and a visual-probe appears in the location previously occupied by one of the pictures. Participants make a choice response according to the location of the probe, and attentional bias is defined as the difference in response time to probes replacing substance-related images and probes replacing neutral images. The rationale here is that participants will be quicker to respond to probes that appear in a location at which they are already attending. Thus, preferential attention allocation toward the substance-related images results in faster responding to probes replacing these images.

There is a large body of evidence that implicates attentional bias in substance use. Alcohol-dependent inpatients showed more attentional bias than did light drinkers on the addiction Stroop task (Johnsen, Laberg, Cox, Vaksdal, \& Hugdahl, 1994). Similarly, alcohol dependent individuals were more distracted by alcohol- 
DRINKING TO DISTRACTION

related stimuli than were nondependent drinkers on a modified flanker task (Cox, Blount, \& Rozak, 2000). Townshend and Duka (2001) demonstrated similar differences between heavy drinkers and light drinkers using a visual-probe task. Field (2005) reported that participants' attentional bias toward cannabis-related words on an addiction Stroop task was correlated with their frequency of cannabis use. A similar relation between attentional bias on a flicker-induced change blindness task and frequency of use was reported in heroin abusers (Bearre, Sturt, Bruce, \& Jones, 2007). These findings are consistent with associative learning accounts of attentional bias, because the number of learning opportunities (i.e., self-administration) is greater in heavy substance-users.

More recently, studies have tested the possibility that acute alcohol administration might increase attentional bias in social drinkers (Duka \& Townshend, 2004; Miller \& Fillmore, 2011; Schoenmakers, Wiers, \& Field, 2008). Individuals attempting to abstain from alcohol use often report that a single drink will increase their desire for alcohol and prompt relapse into excessive use (de Wit, 1996). Indeed, lab studies find that social drinkers who receive an alcohol preload report increased motivation to consume alcohol (Fillmore \& Rush, 2001; Fillmore, 2001) and similar effects have been reported in alcoholics (Hodgson, Rankin, \& Stockwell, 1979). Such priming effects on the motivation to drink following a dose of alcohol also might be indicated by an increase in the drinker's attentional bias.

Duka and Townshend (2004) measured attentional bias of social drinkers in three alcohol dose conditions (i.e., placebo, $0.3 \mathrm{~g} / \mathrm{kg}$, and $0.6 \mathrm{~g} / \mathrm{kg}$ ) using a visual-probe task. These researchers reported attentional bias in the group receiving $0.3 \mathrm{~g} / \mathrm{kg}$ alcohol, whereas no attentional bias was reported in the groups receiving placebo or $0.6 \mathrm{~g} / \mathrm{kg}$ alcohol. These findings were partially replicated by Schoenmakers and others (2008) using the same task: These researchers found that $0.3 \mathrm{~g} / \mathrm{kg}$ alcohol increased attentional bias in heavy drinkers. In a similar study using visual-probe task, our group (Miller \& Fillmore, 2011) examined attentional bias in social drinkers following placebo and two active doses of alcohol (i.e., $0.32 \mathrm{~g} / \mathrm{kg}, 0.64 \mathrm{~g} / \mathrm{kg}$ ), and we found that attentional bias remained unchanged across doses. Results of this study supported the persistence of attentional bias even under a moderate dose of alcohol (i.e., $0.64 \mathrm{~g} / \mathrm{kg}$ ). Evidence for the persistence of attentional bias following alcohol intoxication is important because it indicates that alcohol cues may continue to guide behavior even at elevated blood alcohol concentrations (i.e., BACs $\geq 80 \mathrm{mg} / 100 \mathrm{ml}$ ). This may be important in understanding why some individuals engage in prolonged binge drinking episodes.

If the persistence of attentional bias following alcohol is a factor leading to dysregulated drinking, then one might predict that changes in attentional bias following alcohol will differ between groups at high and low risk to develop alcohol-related problems. For example, high-risk drinkers may show persistence, or even increases, in attentional bias following alcohol, whereas low-risk drinkers may show little change, or possible declines, in attentional bias at similar BACs. One group putatively at-risk for developing alcohol-related problems is young adults with ADHD (Barkley, Murphy, \& Fischer, 2010; Elkins, Mcgue, \& Iacono, 2007). A link between ADHD and alcohol problems has been demonstrated both prospectively (Molina, Pelham, Gnagy, Thompson, \& Marshal, 2007; Mannuzza, Klein, Bessler, Malloy, \& LaPadula, 1998) and cross-sectionally (Glass \& Flory, in press). Recent work has fo- cused on identifying components of the ADHD phenotype that predispose affected individuals to develop substance-related problems (e.g., behavioral disinhibition; Groman, James, \& Jentsch, 2009).

There is compelling evidence that these sober-state cognitive deficits observed in some adults with ADHD (i.e., disinhibition) contribute to the comorbidity between ADHD and alcohol use disorders; however, there is also evidence that group differences in acute alcohol effects may be implicated in this relation. Our group (Weafer, Fillmore, \& Milich, 2009) found that adults with ADHD were more sensitive to the disinhibiting effects of alcohol than were healthy control individuals. Participants in this study were adult drinkers who did not report clinically significant alcoholrelated problems. Thus, it appears that adults with ADHD might show abnormal responses to alcohol, and these abnormal responses may act as a risk factor for later development of alcohol-related problems. Additionally, adults with ADHD have reliably shown attentional dysregulation (e.g., Roberts, Fillmore, \& Milich, 2011), and such deficits may lead to increased attentional bias. Supporting this notion is the finding that attentional disinhibition predicts alcohol use in adults with ADHD (Weafer, Milich, \& Fillmore, 2011).

The current study examined dose-dependent effects of alcohol on attentional bias in adults with ADHD and healthy control adults. Our sample included individuals with no history of problematic alcohol use. By restricting participation to drinkers who did not report clinically significant alcohol-related problems, we were able to examine whether individuals at risk to develop alcohol-use disorders showed abnormal responses to alcohol prior to the development of any alcohol-related problems. A visualprobe task was used to measure attentional bias in 20 adults with ADHD and 20 comparison adults following three doses of alcohol: $0.64 \mathrm{~g} / \mathrm{kg}, 0.32 \mathrm{~g} / \mathrm{kg}$, and $0.0 \mathrm{~g} / \mathrm{kg}$ (placebo). These doses were chosen because prior work has demonstrated the persistence of attentional bias in social drinkers under identical alcohol doses (Miller \& Fillmore, 2011). We predicted that the adults with ADHD would show more attentional bias relative to controls, and that adults with ADHD would show increases in attentional bias following active alcohol doses. Additionally, we examined whether participants' attentional bias would predict their drinking behavior during an ad libitum drinking session. We hypothesized that participants who showed more attentional bias would drink more when given ad libitum access to alcohol. We also hypothesized that attentional bias would be more predictive of ad libitum consumption in the ADHD group.

\section{Method}

\section{Participants}

Participants included 20 adult drinkers with ADHD (15 men and five women; $M$ age $=21.9$ years, $S D=1.1$ year) and 20 adult drinkers with no history of ADHD (16 men and four women; $M$ age $=23.5$ years, $S D=2.1$ year). Participants were recruited through advertisements (i.e., newspaper ads and posters) seeking adults with and without ADHD for a study of the effects of alcohol on computer tasks. Participation was limited to individuals who were between the ages of 21 and 29 and had no uncorrected vision problems. Individuals with past or current severe psychiatric di- 
agnoses other than ADHD (i.e., bipolar disorder, schizophrenia), as determined through self-report and medical records, were not invited to participate. Individuals who reported taking psychotropic medication other than psychostimulant medication for ADHD were not invited to participate. Those who reported infrequent drinking (i.e., less than one drinking occasion per month) or potential risk for alcohol dependence were not invited to participate. Dependence risk was determined by a score of 5 or higher on the Short Michigan Alcoholism Screening Test (Selzer, Vinokur, \& Van Rooijen, 1975). Individuals who reported other high-risk indicators of dependence (e.g., prior treatment for an alcohol use disorder, prior driving under the influence conviction) were excluded from the study. Only volunteers who enjoyed drinking beer were invited to participate, because beer was served during the ad libitum consumption session. Demographic information and selfreported drinking history variables are presented in Table 1.

To ensure that members of the ADHD group experienced symptomatology severe enough to necessitate medication, only volunteers who were currently prescribed medication for ADHD were invited to participate. Members of the ADHD group reported several different prescriptions, including mixed amphetamine salts $(n=15)$, methylphenidate $(n=2)$, and lisdexamphetamine $(n=$ 3). Prescription status was visually confirmed by the experimenter during the first session. Participants were asked to abstain from taking their medication for at least 24 hours prior to each session to ensure that they were unmedicated during the testing sessions.
Participants confirmed compliance with this request at the beginning of each session. Recreational psychostimulant use in the control group was assessed using a life history calendar procedure (LHC; Caspi et al., 1996). Five control participants reported a history of stimulant use. The mean age of first use for these five participants was 18.6 years $(S D=1.9$ years) old. The mean duration of use was 3.2 years $(S D=0.8$ years). The majority of these participants reported infrequent use (i.e., less than once a month; $n=3$ ), although two participants reported moderate use (i.e., once or twice a week and never in large amounts). The LHC was also used to collect information about past marijuana and nicotine use. Thirteen participants in each group reported a history of marijuana use, and the groups did not differ in age of first use $(p=.174)$, frequency of use $(p=.408)$, or duration of use ( $p=$ .909). Thirteen participants in each group reported a history of nicotine use, and the groups did not differ in age of first use ( $p=$ $.408)$, frequency of use $(p=.990)$, or duration of use $(p=.802)$.

ADHD diagnosis was also confirmed by self-report measures of ADHD symptomatology. Participants in the ADHD group were required to meet symptoms-based criteria on at least two of three ADHD scales, including the ADD/H Adolescent Self-Report Scale-Short Form (Robin \& Vandermay, 1996) the Conners Adult ADHD Rating Scale_-Long Form (CAARS—S:L; Conners, Erhardt, \& Sparrow, 1999), and an ADHD Symptom Checklist of 12 ADHD symptoms taken from the diagnostic criteria of the Diagnostic and Statistical Manual of Mental Disorders (DSM-IV,

Table 1

Group Comparisons on Demographic Characteristics, Diagnostic Information, and Self-Reported Drinking Habits

\begin{tabular}{|c|c|c|c|c|c|c|}
\hline & \multicolumn{4}{|c|}{ Group } & \multirow[b]{3}{*}{$t$} & \multirow[b]{3}{*}{$d$} \\
\hline & \multicolumn{2}{|c|}{ Control $(n=19)$} & \multicolumn{2}{|c|}{$\operatorname{ADHD}(n=19)$} & & \\
\hline & Mean & $S D$ & Mean & $S D$ & & \\
\hline \multicolumn{7}{|l|}{ Demographic } \\
\hline Age & 23.6 & 2.1 & 22.0 & 1.2 & $2.9^{* *}$ & 0.97 \\
\hline Gender ( $\%$ male) & 78.9 & & 73.7 & & & \\
\hline Education & 16.0 & 1.8 & 16.2 & 1.4 & 0.4 & 0.13 \\
\hline IQ: Verbal & 104.4 & 12.7 & 108.7 & 10.6 & 1.1 & 0.37 \\
\hline IQ: Nonverbal & 104.5 & 14.1 & 106.8 & 15.2 & 0.5 & 0.17 \\
\hline IQ: Composite & 105.4 & 13.7 & 109.2 & 11.7 & 0.9 & 0.30 \\
\hline \multicolumn{7}{|l|}{ Diagnostic } \\
\hline \multicolumn{7}{|l|}{ CAARS } \\
\hline DSM-IA & 46.8 & 8.5 & 69.9 & 12.2 & $6.8^{* * * * *}$ & 2.26 \\
\hline DSM-HI & 42.6 & 8.0 & 62.9 & 15.4 & $5.1^{* * * *}$ & 1.70 \\
\hline DSM-Tot & 44.3 & 8.3 & 70.4 & 14.6 & $6.8^{* * * *}$ & 2.26 \\
\hline DSM & 1.4 & 2.5 & 6.8 & 2.5 & $8.4^{* * * *}$ & 2.80 \\
\hline AASRS & 8.1 & 5.0 & 18.9 & 3.8 & $7.5^{* * * *}$ & 2.50 \\
\hline BIS & 63.7 & 10.6 & 77.4 & 7.6 & $4.6^{* * * *}$ & 1.53 \\
\hline \multicolumn{7}{|l|}{ Drinking Habits } \\
\hline \multicolumn{7}{|l|}{ TLFB } \\
\hline Drinking Days & 24.5 & 12.7 & 31.7 & 17.5 & 1.5 & 0.50 \\
\hline Total Drinks & 149.5 & 109.3 & 192.7 & 127.5 & 1.1 & 0.37 \\
\hline Drunk Days & 9.9 & 7.7 & 13.5 & 11.1 & 1.3 & 0.43 \\
\hline Binge Days & 14.0 & 10.2 & 18.7 & 11.8 & 1.2 & 0.40 \\
\hline
\end{tabular}

Note. For IQ: Verbal and IQ: Composite comparisons, $n=37, d f=35$. For all other comparisons, $n=38, d f=36$. Age is reported in years. CAARS scores are T-scores; DSM-IA is DSM-IV Inattentive Symptoms, DSM-HI is DSM-IV Hyperactive-Impulsive Symptoms; and DSM-Tot is DSM-IV ADHD Symptoms Total. DSM refers to symptom count on the ADHD symptoms checklist. AASRS refers to total score on the ADD/H Adolescent Self-Report Scale-Short Form. BIS refers to the total score on the Barratt Impulsiveness Scale. TLFB refers to variables reported on the Timeline follow-back procedure. The column labeled " $d$ " reports Cohen's $d$.

${ }^{* * *} p<.01 .{ }^{* * * *} p<.001$. 
$4^{\text {th }}$ ed.; American Psychiatric Association, 1994). All available information pertaining to diagnostic status was reviewed by a licensed clinical psychologist with over 30 years of experience in diagnosing ADHD. This method of diagnosis confirmation has been successfully used by this research group in other studies, and a more detailed description of our diagnostic method is described elsewhere (Roberts et al., 2011). Although the DSM-IV subtype composition of the sample was not assessed, some indication of the subtype makeup of ADHD group is available on the CAARS $-\mathrm{S}$ : L. In the ADHD group, five participants elevated only the DSM-IV Inattentive symptoms subscale, one participant elevated only the $D S M-I V$ Hyperactive/Impulsive symptoms subscale, and nine participants elevated both subscales. Participants completed the 30item Barratt Impulsiveness Scale (Patton, Stanford, \& Barratt, 1995) as an additional measure of impulsivity. The BIS served to further validate group classification. Rating scale scores are reported in Table 1.

\section{Materials}

Visual-probe task. A visual-probe task was used to measure attentional bias toward alcohol-related images. During this task, participants viewed a neutral and an alcohol-related image presented side-by-side on a computer monitor. Upon offset of the images, a visual-probe replaced either the left or right image. Participants were instructed to respond to the visual-probe by pressing one of two response keys on a keyboard to indicate the side on which the target appeared.

The pictures consisted of 10 alcohol-related images that were matched with 10 neutral (i.e., nonalcohol-images). The alcohol images depicted an alcoholic beverage. These images were matched with neutral images consisting of nonalcohol drinks (e.g., a bottle of soda matched with a bottle of beer). All images were photographed against a plain background.

The 10 image pairs were presented four times, once for each of the four possible picture/target combinations (i.e., left and right picture locations and left and right visual-probe locations) for a total of 40 test trials. As is typically done in the visual-probe paradigm (Townshend \& Duka, 2001), there were 40 filler trials which consisted of 10 pairs of neutral images (e.g., a stopwatch) presented four times each. These filler trials were included to reduce the possible habituation to alcohol stimuli that might occur if all trials contained alcohol-related images. The 40 filler trials were intermixed with the 40 test trials, so the task included 80 trials.

Each trial consisted of a set sequence of events. First, a fixation point $(+)$ was presented at the center of the screen for $500 \mathrm{~ms}$. Second, a pair of images was displayed for 1,000 ms. Third, a visual-probe (an " $X$ ") appeared on the left or right side of the screen in the position where one of the pictures was previously displayed. Participants then pressed one of two keys ("> " or " $/$ ") on a standard keyboard to indicate the location of the target. Attentional bias was indicated by faster reaction time (RT) to probes replacing alcohol-related images relative to probes replacing neutral images.

Timeline follow-back. A timeline follow-back procedure (Sobell \& Sobell, 1992) was used to assess daily patterns of alcohol consumption over the past 3 months. Four measures of drinking habits were obtained: (a) total number of drinking days for that period (drinking days), (b) total number of drinks consumed in that period (total drinks), (c) total number of days the participant reported that they felt drunk (drunk days), and (d) total number of days during which binge drinking occurred (binge days). Binge drinking was defined as consuming five or more drinks for men or four or more drinks for women on a single occasion (Wechsler, Dowdall, Davenport, \& Rimm, 1995).

Subjective effects. Participants rated on a visual analog scale (VAS) the degree to which they felt intoxicated and how much they liked the effects of the drug. This method has been used by our group to examine subjective drug effects in previous research studies (Weafer, Camarillo, Fillmore, Milich, \& Marczinski, 2008). Participants indicated how intoxicated they felt (intoxicated) and the degree to which they "liked the alcohol" (like) and "desired more alcohol" (desire) by placing a vertical line on a 100 -mm horizontal line ranging from $0 \mathrm{~mm}$ not at all to $100 \mathrm{~mm}$ very much.

\section{Procedure}

General. Eligible participants made appointments to come to the laboratory for five sessions, including a familiarization session, three alcohol-administration sessions, and an ad libitum drinking session. Sessions were separated by at least 24 hours and participants completed all sessions within 4 weeks. Participants were required to fast for 4 hours prior to each session in which they received alcohol. They were instructed to abstain from consuming alcohol or using other psychoactive drugs 24 hours before each session. Those in the ADHD group were specifically instructed to refrain from taking their medication the day of the session. Prior to each session, participants provided urine samples that were tested for the presence of drug metabolites (ON trak TesTstiks, Roche Diagnostics, Indianapolis, IN). Participants whose urine tested positive for tetrahydrocannabinol (THC) metabolites were asked when they last used marijuana or hashish, and the session continued if their last use was reportedly more than 24 hours before the session. Five participants in the ADHD group and three participants in the control group tested positive for THC during at least one session. Female participants were also tested for HCG in order to verify that they were not pregnant (Mainline Confirms HGL, Mainline Technology, Ann Arbor, MI). Breath samples were taken at the beginning of each session to verify zero BAC (Intoxilyzer, Model 400; CMI, Owensboro, KY).

Familiarization session. All participants completed a familiarization session in which they became acquainted with laboratory procedures, completed questionnaires, provided informed consent for participation, and completed the Kaufman Brief Intelligence Test (Kaufman \& Kaufman, 2004). During this session participants were screened to ensure that they met general criteria for the study. Participants who did not meet criteria for participation in the study were paid $\$ 10$ and discontinued from the study. Participants were familiarized with the visual-probe task and completed a 10-trial familiarization version of the task.

Alcohol-administration sessions. Performance on the visual-probe task was tested under the following three doses of alcohol: $0.64 \mathrm{~g} / \mathrm{kg}, 0.32 \mathrm{~g} / \mathrm{kg}$, and $0.0 \mathrm{~g} / \mathrm{kg}$ (placebo). Following the $0.64 \mathrm{~g} / \mathrm{kg}$, a peak BAC of $80 \mathrm{mg} / 100 \mathrm{ml}$ was expected to occur approximately 75 minutes after drinking began. Following the $0.32 \mathrm{~g} / \mathrm{kg}$ alcohol, a peak BAC of approximately $40 \mathrm{mg} / 100 \mathrm{ml}$ was 
expected to occur approximately 40 minutes after beverage administration. These peak BAC estimates were based on prior work in our lab using similar alcohol doses (Fillmore \& Blackburn, 2002; Miller \& Fillmore, 2011). Dose order was randomized across subjects, and doses were calculated based on body weight. The alcohol beverages were served as one part alcohol and three parts carbonated mix divided equally into two glasses. The placebo beverage consisted of four parts carbonated mix that matched the volume of the $0.32 \mathrm{~g} / \mathrm{kg}$ alcohol beverage. Five $\mathrm{ml}$ of alcohol was floated on the top of each placebo glass, and the glasses were sprayed with an alcoholic mist that resembled condensation and provided a strong alcohol odor. Previous research has shown that individuals report that these beverages contain alcohol (Fillmore \& Blackburn, 2002). Participants were instructed to consume the first serving within two minutes and the second serving within four minutes. The visual-probe task was performed 25 minutes after beverage administration. Subjective effects were measured 60 minutes after beverage administration. Breath samples were collected at 20,45, 60, and 70 minutes following beverage administration during both the placebo and alcohol test sessions. After testing, participants remained at leisure in a lounge area until their BAC fell to $20 \mathrm{mg} / 100 \mathrm{ml}$ or below, at which time they were allowed to leave. Participants were provided with transportation as needed.

Ad libitum drinking session. Participants' ad libitum alcohol consumption was measured during the final session. Participants completed a taste-rating task (Marlatt, Demming, \& Reid, 1973), which previous research has demonstrated as a valid measure of ad libitum alcohol consumption (Collins, Gollnisch, \& Izzo, 1996; Marczinski, Bryant, \& Fillmore, 2005). Participants received six different $355 \mathrm{ml}$ beers and asked to rate them on various hedonic qualities (e.g., aroma, taste) using Likert scales, ostensibly to provide information on college students' beer preferences. The beers were served in six clear and frosted glasses that were color-coded by a rubber band placed around the bottom of the glass. The beers sampled were Michelob Light ${ }^{\mathrm{TM}}$, Rolling Rock ${ }^{\mathrm{TM}}$, Harp $^{\mathrm{TM}}$, Bud Light ${ }^{\mathrm{TM}}$, Coors Light ${ }^{\mathrm{TM}}$, and Samuel Adams Light ${ }^{\mathrm{TM}}$. We chose these beers because they are representative of beers commonly consumed by young adults, and they are all similar in per volume alcohol content $(4.5 \%, 4.5 \%, 4.6 \%, 3.6 \%, 4.4 \%$, and $4.1 \%$, respectively).

Participants were told that they would be able to sample the beers for 90 minutes. They were invited to drink as much or as little of each beer as they liked, but instructed to sample enough of each beer to give accurate ratings. The session took place in a room designed to approximate a college dormitory. Posters with slogans relating to beer and partying were hung on the walls, and participants were seated in a comfortable recliner. Beers that were not being sampled were kept in a miniature refrigerator. A TV and DVD player were also available to provide entertainment during the session. Ad libitum sessions were held individually for each participant.

After the 90 minute sampling period, participants' BACs were measured and the six glasses were removed from the testing room. The remaining beer was measured and subtracted from the total amount of beer presented to determine the amount of beer consumed by the participant. Participants remained in the lab until their BAC fell below $20 \mathrm{mg} / 100 \mathrm{ml}$, at which time they were debriefed and released.

\section{Results}

\section{Covariate and Outlier Analyses}

A chi-square analysis found that gender make-up was independent of group, $\chi^{2}(1, \mathrm{~N}=38)=0.15, p=.703$. As seen in Table 1 , groups differed significantly in age. Age was not significantly correlated with any criterion variable, so results are presented without the inclusion of age as a covariate. No outliers were identified. Data for two participants were removed from the study following data collection: One participant in the control group reported prior experience with an ad libitum drinking task, and one participant in the ADHD group failed to understand task instructions. Data from these participants were removed from the analyses.

\section{Self-Reported Drinking Habits}

Groups were compared on self-reported drinking habits to determine whether group differences in attentional bias may be attributable to differences in drinking habits outside of the laboratory. As seen in Table 1, there were no significant differences in drinking habits between groups.

\section{Blood Alcohol Concentrations}

No detectable BACs were observed in the placebo condition. A 2 (dose) $\times 2$ (group) $\times 4$ (time) mixed-design ANOVA tested group differences in BAC. No significant main effect or interaction involving group was observed, $p \mathrm{~s}>.456$. There was a significant main effect of time owing to the rise and fall of BAC over the course of the sessions, $F(3,108)=54.5, p>.001$, and a significant main effect of dose resulting from larger BACs in the $0.64 \mathrm{~g} / \mathrm{kg}$ condition, $F(1,36)=322.5, p<.001$. There was a significant dose $\mathrm{x}$ time interaction owing to a larger BAC curve following $0.64 \mathrm{~g} / \mathrm{kg}$ alcohol, $F(3,108)=28.9, p>.001$. These data confirm that BACs were comparable between groups. Following $0.32 \mathrm{~g} / \mathrm{kg}$ alcohol, mean BACs during the 20, 45, 60, and 70 minute measurements were $34.7 \mathrm{mg} / 100 \mathrm{ml}(S D=12.1), 40.4$ $\mathrm{mg} / 100 \mathrm{ml}(S D=9.7), 30.9 \mathrm{mg} / 100 \mathrm{ml}(S D=6.3)$, and 24.4 $\mathrm{mg} / 100 \mathrm{ml}(S D=5.9)$, respectively. Following $0.64 \mathrm{~g} / \mathrm{kg}$ alcohol, mean BACs during the 20,45, 60, and 70 minute measurements were $65.4 \mathrm{mg} / 100 \mathrm{ml}(S D=20.1), 94.0 \mathrm{mg} / 100 \mathrm{ml}(S D=24.9)$, $83.0(S D=18.6)$, and $73.7 \mathrm{mg} / 100 \mathrm{ml}(S D=15.7)$, respectively.

\section{Subjective Effects}

Subjective ratings of intoxication, liking, and desire are presented in Table 2. Group differences were examined using a series of 2 (group) $\times 3$ (dose) mixed-design ANOVAs. There was a main effect of dose on subjective intoxication, $F(2,72)=125.8, p<.001$, liking, $F(2,72)=35.0$, and desire, $F(2,72)=7.2, p=.001$. No significant main effect or interaction involving group was observed, $p \mathrm{~s}>.753$.

\section{Visual-Probe Dose Effects}

Our first hypothesis that participants in the ADHD group would show larger increases in attentional bias following active doses than the control group was tested using a series of mixed-design and repeated measure ANOVAs. The effects of alcohol dose on attentional bias were examined using a 2 (group) $\times 2$ (picture 
Table 2

Subjective Drug Effects

\begin{tabular}{|c|c|c|c|c|c|c|}
\hline \multirow{3}{*}{$\begin{array}{l}\text { VAS } \\
\text { Rating }\end{array}$} & \multicolumn{6}{|c|}{ Dose } \\
\hline & \multicolumn{2}{|c|}{$0.0 \mathrm{~g} / \mathrm{kg}$ (Placebo) } & \multicolumn{2}{|c|}{$0.32 \mathrm{~g} / \mathrm{kg}$} & \multicolumn{2}{|c|}{$0.64 \mathrm{~g} / \mathrm{kg}$} \\
\hline & Control & ADHD & Control & ADHD & Control & ADHD \\
\hline Like & $30.6(23.7)$ & $26.7(24.6)$ & $43.2(16.8)$ & $44.7(17.9)$ & $60.5(16.3)$ & $60.2(21.7)$ \\
\hline Desire & $20.5(23.8)$ & $17.0(24.9)$ & $27.4(23.3)$ & $26.5(22.7)$ & $35.5(24.8)$ & $35.3(28.2)$ \\
\hline Intoxicated & $10.9(16.1)$ & $10.9(16.3)$ & $33.4(22.5)$ & $33.8(19.7)$ & $59.7(22.8)$ & $58.4(18.7)$ \\
\hline
\end{tabular}

Note. Reported values are mean (SD) responses on the visual analogue scale.

type) $\times 3$ (dose) mixed-design ANOVA. The main effect of dose approached significance, $F(2,72)=2.8, p=.067$, owing to slower RT under active alcohol doses. There was a significant main effect of picture type, $F(1,36)=17.3, p<.001$. RT to probes replacing alcohol pictures $(M=423.1 \mathrm{~ms}, S D=50.2 \mathrm{~ms})$ was faster than RT to probes replacing neutral pictures $(M=435.7$ $\mathrm{ms}, S D=57.5 \mathrm{~ms})$. The dose $\times$ picture type interaction, $F(2$, $72)=6.03, p=.004$, and dose $\mathrm{x}$ picture type $\mathrm{x}$ group interaction, $F(2,72)=3.1, p=.053$, were both significant. This three way interaction was examined using 2 (picture type) $\times 3$ (dose) reduced model repeated measure ANOVAs within each group. In the control group, there was a marginally significant main effect of picture type, $F(1,18)=4.1, p=.057$, but no dose $\mathrm{x}$ picture type interaction, $F(2,36)=0.5, p=.600$. In the ADHD group, there was a significant main effect of picture type, $F(1,18)=18.7, p<$ .001 , and a significant dose $\mathrm{x}$ picture type interaction, $F(2,36)=$ $5.5, p=.008$. As seen in Figure 1, this significant dose $\mathrm{x}$ picture type interaction in the ADHD group reflects increased attentional bias following active alcohol doses.

We conducted two sets of planned comparisons. First, planned $t$ tests compared the magnitude of attentional bias under each active dose to placebo. For these comparisons, attentional bias under a dose condition was measured as a single difference score by subtracting the RT to probes replacing alcohol images from the RT to probes replacing neutral images. In the ADHD group, attentional bias was greater following both active doses compared to placebo, $p \mathrm{~s}<.012$. An identical set of a priori comparisons were conducted within the control group, and there were no significant differences in attentional bias among dose conditions, $p s>.596$. Second, we compared attentional bias under each alcohol dose between groups using planned one-tailed $t$ tests. Although the ADHD group did not show more attentional bias than the control group under placebo $(p=.861)$, there were significant differences between groups under $0.64 \mathrm{~g} / \mathrm{kg}$ alcohol $(p=.027)$ and the difference between groups under $0.32 \mathrm{~g} / \mathrm{kg}$ alcohol approached significance, $p=.060$.

\section{Ad Libitum Drinking Session}

The primary measure of interest for the ad libitum session was the amount of beer consumed. The control group $(M=1,400 \mathrm{ml}$, $S D=487)$ and the ADHD group $(M=1,309 \mathrm{ml}, S D=586) \mathrm{did}$ not differ in ad libitum consumption, $t(36)=0.5, p=.606, d=$ .17. BAC was measured after the ad libitum session was completed: the control group $(M=62.9 \mathrm{mg} / 100 \mathrm{ml}, S D=23.2)$ and the ADHD group $(M=50.8 \mathrm{mg} / 100 \mathrm{ml}, S D=28.7)$ did not differ significantly on obtained BAC, $t(36)=1.4, p=.161, d=.48$. Consistent with Weafer and Fillmore (2008), ad libitum consumption showed a significant positive relation with self-reported drinking habits. These correlations are presented in Table 3.

Ad libitum consumption in relation to attentional bias. The relations of attentional bias to ad libitum consumption were examined using multiple regression analyses. In these analyses
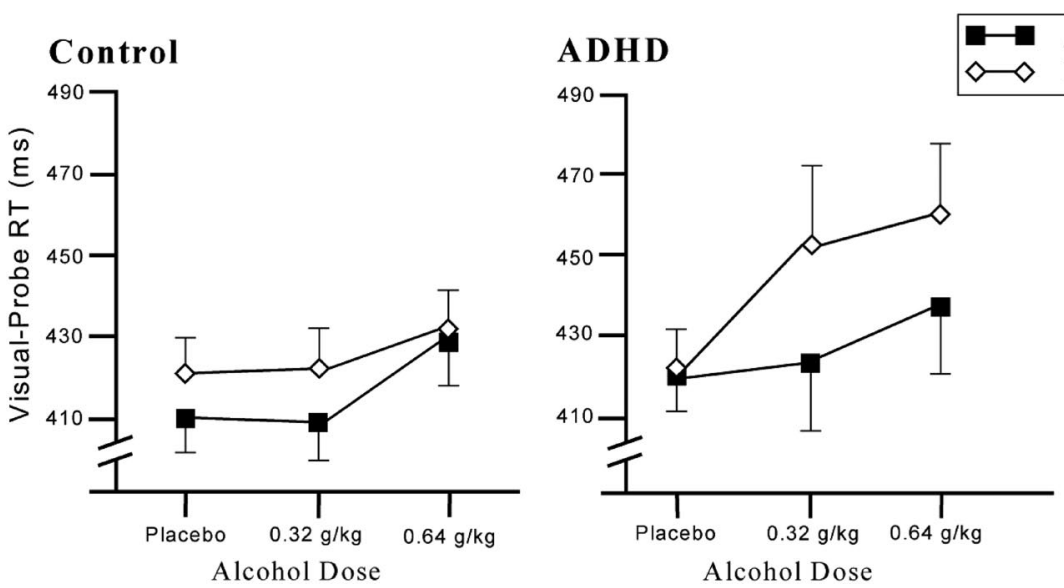

Figure 1. Mean RT $(+S E)$ to visual-probes replacing alcohol and neutral images of the attention-deficit/ hyperactivity disorder and control groups. 
Table 3

Correlations of Ad Libitum Consumption With Self-Reported Drinking Behavior

\begin{tabular}{lll}
\hline & \multicolumn{2}{c}{ Ad Libitum Drinking Session } \\
\cline { 2 - 3 } & ml Consumed & BAC \\
\hline TLFB & & .20 \\
Total Drinks & $.45^{* *}$ & $.33^{*}$ \\
Drinking Days & .21 & $.32^{*}$ \\
Binge Days & $.47^{* *}$ & .17 \\
Drunk Days & $.40^{*}$ & \\
\hline
\end{tabular}

Note. For all correlations, $n=38, d f=36$. BAC is blood alcohol concentration measured directly after completion of the ad libitum session. ${ }^{*} p<.05 .{ }^{* *} p<.01$

group status and attentional bias scores were regressed onto ad libitum consumption. Three regression models were fit: attentional bias in each dose condition was entered into a separate model alongside group status. We specified that only models in which attentional bias significantly predicted ad libitum consumption would be tested for group $\mathrm{x}$ attentional bias interaction. In these models, attentional bias following placebo, $\beta=-0.02$, $S E=0.17$, $p=.919$, and $0.32 \mathrm{~g} / \mathrm{kg}$ alcohol, $\beta=-0.14, S E=0.17, p=.409$, were not predictive of ad libitum consumption; however, attentional bias following $0.64 \mathrm{~g} / \mathrm{kg}$ alcohol showed a significant relation with ad libitum consumption, $\beta=0.45, S E=0.16, p=.008$.

Having identified a relation between attentional bias and ad libitum consumption, we tested the hypothesis that attentional bias was more predictive of alcohol consumption in the ADHD group than the control group. The three predictors were regressed onto ad libitum consumption using hierarchical regression analyses. In these analyses, group status and attentional bias following $0.64 \mathrm{~g} / \mathrm{kg}$ alcohol were entered in the first step, and a group $\mathrm{x}$ attentional bias interaction term was entered in the second step. As seen in Table 4, the group $\times$ attentional bias interaction term accounted for incremental variance in ad libitum consumption. Bivariate regression analyses were used to examine the significant group $\mathrm{x}$ attentional bias interaction term. Specifically, attentional bias following $0.64 \mathrm{~g} / \mathrm{kg}$ alcohol was regressed onto ad libitum consumption within each group. In the control group, attentional bias did not predict ad libitum consumption, $R^{2}=.04, F(1,17)=$ $0.7, p=.431$. In the ADHD group, however, attentional bias significantly predicted ad libitum consumption, $R^{2}=.44, F(1$,
$17)=13.6, p=.002$. These relations are presented separately by group in Figure 2.

Ad libitum consumption in relation to subjective alcohol effects. We also examined whether subjective ratings of intoxication, liking, and desire predicted ad libitum consumption in either group and in the sample as a whole. No significant correlations of ad libitum consumption with subjective effects were observed in any of the dose conditions, $r \mathrm{~s}<.25, p \mathrm{~s}>.127$.

\section{Discussion}

This study examined acute alcohol effects on attentional bias in adults with and without ADHD. For participants in the control group, attentional bias was relatively stable across doses. This is consistent with prior research demonstrating that attentional bias persists in social drinkers under moderate doses of alcohol (Miller \& Fillmore, 2011). Conversely, attentional bias was induced in the ADHD group following active alcohol doses. This group difference cannot be attributed to differences in drinking habits or BACs during testing, because groups were similar on these measures. We also examined the degree to which attentional bias predicted ad libitum alcohol consumption. Attentional bias following $0.64 \mathrm{~g} / \mathrm{kg}$ alcohol was predictive of ad libitum consumption, and this relation was observed only in the ADHD group. This is consistent with our prediction that attentional bias is a stronger determinant of drinking behavior in the ADHD group. These findings provide evidence for alcohol-induced increases in attentional bias in adults with ADHD and implicate attentional bias in the drinking behavior of this group.

There may be several reasons why alcohol increased attentional bias in the ADHD group. First, it is possible ADHD participants experienced the euphoric effects of the alcohol to a greater degree than did control participants. However, there were no group differences in self-reported reinforcing effects (e.g., liking, desire) following alcohol. Instead, increased attentional bias among those with ADHD might represent an abnormal response to reinforcement in this group. Ströhle and colleagues (2008) reported that adults with ADHD show reduced activity in the ventral striatum when cued to anticipate reward and increased activity in the orbitofrontal cortex in response to reward outcome. Consistent with these findings, participants in the ADHD group showed no attentional bias in the placebo condition and exaggerated attentional bias following active doses. This may reflect the deficits in reward anticipation observed in this group. Further, the increase in attentional bias following a priming dose may reflect increased sensitivity to the acute reinforcing effects of alcohol.

Table 4

Hierarchical Multiple Regression Analyses Predicting Ad Libitum Consumption From Attentional Bias Following $0.64 \mathrm{~g} / \mathrm{kg}$ Alcohol and Diagnostic Status

\begin{tabular}{|c|c|c|c|c|c|c|c|c|}
\hline Variable & $d f$ & $\beta$ & $S E \beta$ & $r_{\text {semipartial }}$ & $\Delta R^{2}$ & $\Delta F$ & $\Delta p$ & $p$ \\
\hline Step 1 & 2,35 & & & & .19 & 4.1 & .026 & \\
\hline Group & & -0.23 & 0.16 & -.22 & & & & .165 \\
\hline Attentional Bias & & 0.45 & 0.16 & .43 & & & & .008 \\
\hline Step 2 & 3,34 & & & & .09 & 4.5 & .037 & \\
\hline Group*Attentional Bias & & 0.48 & 0.23 & .31 & & & & .041 \\
\hline
\end{tabular}



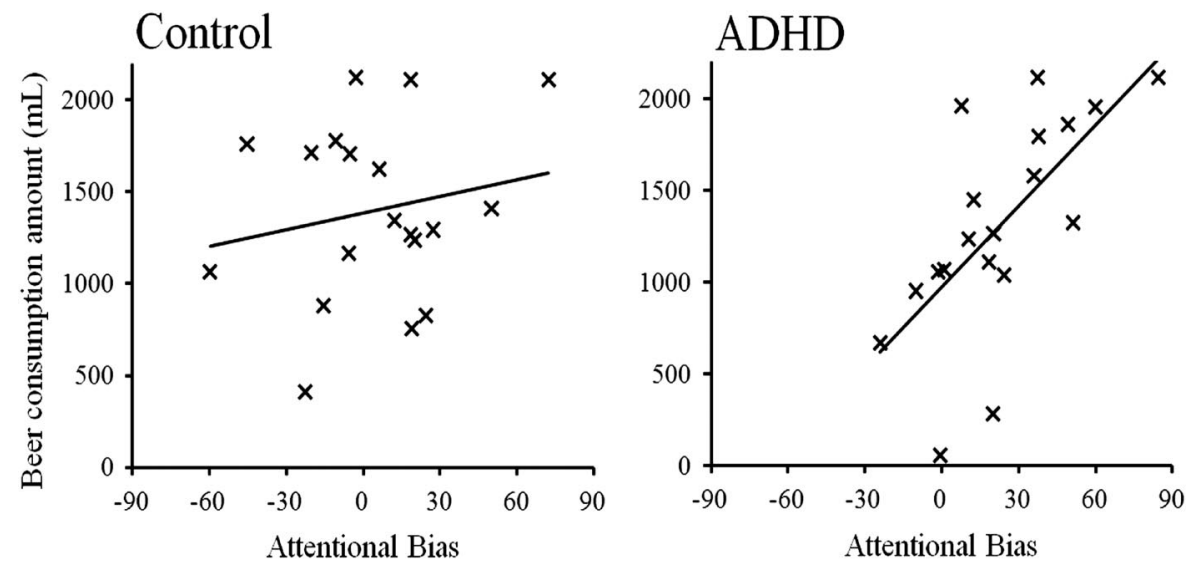

Figure 2. Relation between attentional bias following $0.64 \mathrm{~g} / \mathrm{kg}$ alcohol (i.e., difference in mean RT between visual-probes replacing neutral images and visual-probes replacing alcohol images) and ad libitum consumption in the attention-deficit/hyperactivity disorder and control groups.

Attentional bias, as measured by the visual-probe task, is defined as the difference in RT to probes replacing alcohol and neutral images. Attentional bias can be increased by speeding the responses to probes associated with alcohol images or alternatively by slowing responses to probes associated with neutral images. In the current study, alcohol increased the magnitude of attentional bias in the ADHD group despite a general slowing of responses to probes associated with both types of images, especially neutral images. Considering this, one might argue that alcohol caused participants to attend less closely to neutral cues rather than increasing attention toward alcohol cues. However, as a general CNS depressant, alcohol is well-known for its slowing effect on RT at these doses (Fillmore, 2007; Koelega, 1995). As such, this general performanceimpairing effect of the drug needs to be considered when evaluating its effect on RTs in the attentional bias task. Following $0.64 \mathrm{~g} / \mathrm{kg}$ alcohol, some slowing of RT would be expected in this task regardless of probe condition. The fact that the ADHD group showed minimal slowing to probes associated with alcohol images, even at this dose, likely indicates that they were closely attending to these images, so that they were prepared to quickly respond to the probe when it appeared. Indeed, studies show that stimulus conditions such as predictive cues can increase drinker's preparedness to respond to target stimuli, and this offsets some of the slowing effects of alcohol (Marczinski \& Fillmore, 2003). Much in the same manner, the ADHD drinkers' biased attention to alcohol images in the current study might have served to increase their response preparation to the probes, offsetting the slowing effects of alcohol. In sum, these findings call attention to the importance of considering the direct effect of drugs on the performance indicators of attentional bias (e.g., RT) when examining participants' attentional bias in a drugged state.

Evidence of increased attentional bias following an alcohol dose in adults with ADHD is noteworthy because it contrasts acute alcohol effects on attentional bias in healthy social drinkers. Further, these findings have important implications for understanding why adults with ADHD are at increased risk for harmful drinking. ${ }^{1}$ Considering this increase in attentional bias in the context of a binge drinking episode, adults with ADHD may have more difficulty stopping a drinking session as they become more intoxicated. Interestingly, adults with ADHD did not show elevated attentional bias following placebo, so these adults may not be more likely to initiate a drinking session. However, once a drinking session has begun, it may become more difficult for these individuals to stop drinking as they become more focused on alcohol cues. The close relation between their attentional bias following alcohol and their ad libitum consumption also supports the idea that attentional bias under alcohol continues to influence how much is consumed during a drinking episode. This finding is particularly noteworthy because those in the ADHD group continued to show attentional bias at BACs sufficient to meet criteria for binge drinking (i.e., 80 $\mathrm{mg} / 100 \mathrm{ml}$; NIAAA, 2004). Compounding this risk factor is the increased sensitivity to the disinhibiting effects of alcohol in adults with ADHD (Weafer et al., 2009). This increased sensitivity to the disinhibiting effects of alcohol may complement alcohol-induced increases in attentional bias as a risk factor for dyscontrolled drinking in adults with ADHD. Taken together, these findings provide evidence that alcohol acts to alter cognitive processes in a way that could increase drinking in adults with ADHD.

It is important to note that attentional bias was not predictive of ad libitum consumption among members of the control group. This finding might be explained by group differences in behavioral control over reward-driven impulses. Specifically, adults with ADHD have more difficulty inhibiting impulsive responses when presented with a cue for reward (Scheres, Lee, \& Sumiya, 2008). Taken together with our data, these findings suggest that alcoholrelated cues in the environment may exert greater influence over drinking behavior in adults with ADHD for whom alcohol cues are perceived as motivationally relevant. This group difference also supports dual-process models of substance use. These models recognize that both explicit (e.g., expectancies) and implicit (e.g., attentional bias) cognitions can guide decisions to use substances

\footnotetext{
${ }^{1}$ The finding that ADHD is associated with increased alcohol consumption was not replicated in our data; however, this effect has been shown in prior research (Molina \& Pelham, 2003; Glass \& Flory, in press). Our null findings here are likely due to the small sample size and our conservative method for screening out individuals at risk for substance abuse and dependence.
} 
(Stacy \& Wiers, 2010). According to these models, explicit cognitive processes guide substance use under normal circumstances, whereas implicit cognitive processes are more predictive of substance use under conditions of limited self-control. Supporting this is our finding that attentional bias is a stronger predictor of ad libitum drinking in a group characterized by impaired self-control (i.e., adults with ADHD; Barkley, 1997).

The current research contributes to our understanding of risk factors for alcohol problems; however, results should be interpreted in light of some limitations. First, the sample included only individuals who were between 21 and 29 years old, so generalizing these findings to adolescents and older adults with ADHD may not be appropriate. Second, participants who reported symptoms of alcohol dependence were excluded from participation. It is likely that cognitive determinants of drinking behavior differ in individuals with alcohol dependence, and generalizing our findings to this group may not be appropriate. Third, our diagnostic strategy may have been strengthened by the inclusion of a clinical interview and informant report questionnaires to substantiate the self-report symptom inventories. Fourth, there is a possibility that medication carryover effects influenced attentional bias of participants who took their ADHD medication the day before testing. However, our 24 hour washout period is consistent with other studies involving medicated adults with ADHD (e.g., Lovejoy et al., 1999; Nigg, Butler, Huang-Pollock, \& Henderson, 2002) and based on the medication pharmacokinetics probably allowed sufficient time to prevent the influence of any residual drug metabolites at the time of testing (Patrick \& Markowitz, 1997). Finally, attentional bias in the ADHD group may have been influenced by their prior treatment with stimulant medication. Participation in the ADHD group was limited to diagnosed adults who were prescribed ADHD medication. There is some evidence that previous exposure to $d$-amphetamine increases abuse potential of alcohol. Long-term $d$-amphetamine exposure increases ad libitum alcohol consumption in rats (Fahlke, Hansen, Engel, \& Hard, 1994). A similar pattern has been shown in human adults: Moderate drinkers worked for more $d$-amphetamine and reported significantly greater subjective effects than did light drinkers (Stanley, Poole, Stoops, \& Rush, 2011). Taken together, these studies provide evidence for cross-sensitization between alcohol and amphetamine. Determining the relative contributions of prior stimulant exposure and innate neurological differences to the alcohol-induced increases in attentional bias in the ADHD group will require additional research.

In sum, the current study provided evidence for alcohol-induced increases in attentional bias in adults with ADHD. This abnormal response to alcohol may contribute to the increased risk for developing alcohol related problems in this at-risk group. In examining factors placing adults with ADHD at increased risk to develop alcohol-related problems, prior literature has focused on soberstate abnormalities in this population (Groman et al., 2009). However, our results highlight group differences in acute drug effects as a factor placing adults with ADHD at higher risk for developing alcohol-related problems.

\section{References}

American Psychiatric Association. (1994). Diagnostic and statistical manual of mental disorders (4th ed.). Washington, DC: Author.
Barkley, R. A., Murphy, K. R., \& Fischer, M. (2010). ADHD in adults: What the science says. New York, NY: Guilford Press.

Barkley, R. A. (1997). Behavioral inhibition, sustained attention, and executive functions: Constructing a unifying theory of ADHD. Psychological Bulletin, 121, 65-94. doi:10.1037/0033-2909.121.1.65

Bearre, L., Sturt, P., Bruce, G., \& Jones, B. T. (2007). Heroin-related attentional bias and monthly frequency of heroin use are positively associated in attenders of a harm reduction service. Addictive Behaviors, 32, 784-792. doi:10.1016/j.addbeh.2006.06.019

Caspi, A., Moffitt, T. E., Thornton, A., Freedman, D., Arnell, J., Harrington, H., Smeigers, J., \& Silva, P. A. (1996). The life-history calendar: A research and clinical assessment method for collecting retrospective event-history data. International Journal of Methods in Psychiatric Research, 6, 101-114. doi:10.1002/(SICI)1234-988X(199607)6:2<101::AID-MPR156>3.3.CO; 2-E

Collins, R. L., Gollnisch, G., \& Izzo, C. V. (1996). Drinking restraint and alcohol-related outcomes: Exploring the contributions of beverage instructions, beverage content and self-monitoring. Journal of Studies on Alcohol, 57, 563-571.

Conners, C. K., Erhardt, D., \& Sparrow, E. P. (1999). Conners' adult ADHD rating scales. Toronto, Canada: Multi-Health Systems.

Cox, W. M., Blount, J. P., \& Rozak, A. M. (2000). Alcohol abusers' and nonabusers' distraction by alcohol and concern-related stimuli. American Journal of Drug and Alcohol Abuse, 26, 489-495. doi:10.1081/ ADA-100100258

Cox, W. M., Fadardi, J. S., \& Pothos, E. M. (2006). The addiction-Stroop test: Theoretical considerations and procedural recommendations. Psychological Bulletin, 132, 443-476. doi:10.1037/0033-2909.132.3.443

de Wit, H. (1996). Priming effects with drugs and other reinforcers. Experimental and Clinical Psychopharmacology, 4, 5-10. doi:10.1037/ 1064-1297.4.1.5

Duka, T., \& Townshend, J. M. (2004). The priming effect of alcohol pre-load on attentional bias to alcohol-related stimuli. Psychopharmacology, 176, 353-356. doi:10.1007/s00213-004-1906-7

Elkins, I. J., Mcgue, M., \& Iacono, W. G. (2007). Prospective effects of attention-deficit/hyperactivity disorder, conduct disorder, and sex on adolescent substance use and abuse. Archives of General Psychiatry, 64, $1145-1152$ .64 .10 .1145

Fahlke, C., Hansen, S., Engel, J. A., \& Hard, E. (1994). Effects of ventral striatal 6-OHDA lesions or amphetamine sensitization on ethanol consumption in the rat. Pharmacology Biochemistry and Behavior, 47, 345-349. doi:10.1016/0091-3057(94)90020-5

Field, M., \& Cox, W. M. (2008). Attentional bias in addictive behaviors: A review of its development, causes, and consequences. Drug and Alcohol Dependence, 97, 1-20. doi:10.1016/j.drugalcdep.2008.03.030

Field, M. (2005). Cannabis 'dependence' and attentional bias for cannabisrelated words. Behavioural Pharmacology, 16, 473-476. doi:10.1097/ 00008877-200509000-00021

Fillmore, M. T., \& Blackburn, J. (2002). Compensating for alcoholinduced impairment: Alcohol expectancies and behavioral disinhibition. Journal of Studies on Alcohol, 63, 237-246.

Fillmore, M. T., \& Rush, C. R. (2001). Alcohol effects on inhibitory and activational response strategies in the acquisition of alcohol and other reinforcers: Priming the motivation to drink. Journal of Studies on Alcohol, 62, 646-656.

Fillmore, M. T. (2001). Cognitive preoccupation with alcohol and binge drinking in college students: Alcohol-induced priming of the motivation to drink. Psychology of Addictive Behaviors, 15, 325-332. doi:10.1037/ 0893-164X.15.4.325

Fillmore, M. T. (2007). Acute alcohol-induced impairment of cognitive functions: Past and present findings. International Journal on Disability and Human Development, 6, 115-125. doi:10.1515/IJDHD.2007.6.2.115

Glass, K., \& Flory, K. (in press). Are symptoms of ADHD related to 
substance use among college students? Psychology of Addictive Behaviors.

Groman, S. M., James, A. S., \& Jentsch, J. D. (2009). Poor response inhibition: At the nexus between substance abuse and attention deficit/hyperactivity disorder. Neuroscience and Biobehavioral Reviews, 33, 690-698. doi: 10.1016/j.neubiorev.2008.08.008

Hodgson, R., Rankin, H., \& Stockwell, T. (1979). Alcohol dependence and the priming effect. Behaviour Research and Therapy, 17, 379-387.

Johnsen, B. H., Laberg, J. C., Cox, W. M., Vaksdal, A., \& Hugdahl, K. (1994). Alcoholic subjects' attentional bias in the processing of alcoholrelated words. Psychology of Addictive Behaviors, 8, 111-115. doi: 10.1037/0893-164X.8.2.111

Jones, B. T., Bruce, G., Livingstone, S., \& Reed, E. (2006). Alcohol-related attentional bias in problem drinkers with the flicker change blindness paradigm. Psychology of Addictive Behaviors, 20, 171-177. doi: 10.1037/0893-164X.20.2.171

Kaufman, A. S., \& Kaufman, N. L. (2004). Kaufman Brief Intelligence Test: Manual. Circle Pines, MN: American Guidance Service.

Klinger, E., \& Cox, W. M. (2004). Motivation and the theory of current concerns. In W. M. Cox \& E. Klinger (Eds.), Handbook of motivational counseling: Concepts, approaches, and assessment. (pp. 3-23). Chichester, England: Wiley. doi:10.1002/9780470713129.ch1

Koelega, H. S. (1995). Alcohol and vigilance performance: A review. Psychopharmacology, 118, 233-249. doi:10.1007/BF02245951

Lovejoy, D. W., Ball, J. D., Keats, M., Stutts, M. L., Spain, E. H., Janda, L., \& Janusz, J. (1999). Neuropsychological performance of adults with attention deficit hyperactivity disorder (ADHD): Diagnostic classification estimates for measures of frontal lobe/executive functioning. Journal of the International Neuropsychological Society, 5, 222-233. doi:10.1017/ S1355617799533055

Mannuzza, S., Klein, R. G., Bessler, A., Malloy, P., \& LaPadula, M. (1998). Adult psychiatric status of hyperactive boys grown up. American Journal of Psychiatry, 155, 493-498.

Marczinski, C. A., Bryant, R., \& Fillmore, M. T. (2005). The relationship between cognitive preoccupation with alcohol and alcohol use in male and female college students. Addiction Research and Theory, 13, 383-394. doi:10.1080/16066350500150665

Marczinski, C. A., \& Fillmore, M. T. (2003). Preresponse cues reduce the impairing effects of alcohol on the execution and suppression of responses. Experimental and Clinical Psychopharmacology, 11, 110-117. doi:10.1037/1064-1297.11.1.110

Marlatt, G. A., Demming, B., \& Reid, J. B. (1973). Loss of control drinking in alcoholics: An experimental analogue. Journal of Abnormal Psychology, 81, 233-241. doi:10.1037/h0034532

Miller, M. A., \& Fillmore, M. T. (2011). Persistence of attentional bias toward alcohol-related stimuli in intoxicated social drinkers. Drug and Alcohol Dependence, 117, 184-189. doi doi:10.1016/j.drugalcdep.2011.01.016

Molina, B. S. G., \& Pelham, W. E., Jr. (2003). Childhood predictors of adolescent substance use in a longitudinal study of children with ADHD. Journal of Abnormal Psychology, 112, 497-507. doi:10.1037/0021843X.112.3.497

Molina, B. S., Pelham, W. E., Gnagy, E. M., Thompson, A. L., \& Marshal, M. P. (2007). Attention-deficit/hyperactivity disorder risk for heavy drinking and alcohol use disorder is age specific. Alcoholism: Clinical and Experimental Research, 31, 643-654. doi:10.1111/j.15300277.2007.00349.x

National Institute on Alcohol Abuse and Alcoholism. (2004, Winter). NIAAA council approves definition of binge drinking. NIAAA Newsletter, No. 3.

Nigg., J. T., Butler, K. M., Huang-Pollock, C. L., \& Henderson, J. M. (2002). Inhibitory processes in adults with persistent childhood onset ADHD. Journal of Consulting and Clinical Psychology, 70, 153-157. doi:10.1037/0022-006X.70.1.153
Patrick, K. S., Markowitz, J. S. (1997). Pharmacology of methylphenidate, amphetamine, enantiomers, and pemoline in attention-deficit hyperactivity disorder. Human Psychopharmacology, 12, 527-546. doi:10.1002/ (SICI) 1099-1077(199711/12)12:6<527::AID-HUP932>3.0.CO;2-U

Patton, J. H., Stanford, M. S., \& Barratt, E. S. (1995). Factor structure of the Barratt impulsiveness scale. Journal of Clinical Psychology, 51, 768-774. doi:10.1002/1097-4679(199511)51:6<768::AIDJCLP2270510607>3.0.CO;2-1

Robbins, S. J. R., \& Ehrman, R. N. (2004). The role of attentional bias in substance abuse. Behavioral and Cognitive Neuroscience Reviews, 3, 243-260. doi:10.1177/1534582305275423

Roberts, W., Fillmore, M. T., \& Milich, R. (2011). Separating automatic and intentional inhibitory mechanisms of attention in adults with attention-deficit/hyperactivity disorder. Journal of Abnormal Psychology, 120, 223-233. doi:10.1037/a0021408

Robin, A. L., \& Vandermay, S. J. (1996). Validation of a measure for adolescent self-report of attention deficit disorder symptoms. Journal of Developmental \& Behavioral Pediatrics, 17, 211-215. doi:10.1097/ 00004703-199608000-00001

Robinson, T. E., \& Berridge, K. C. (1993). The neural basis of drug craving: An incentive-sensitization theory of addiction. Brain Research Reviews, 18, 247-291. doi:10.1016/0165-0173(93)90013-P

Scheres, A., Lee, A., \& Sumiya, M. (2008). Temporal reward discounting and ADHD: Task and symptom specific effects. Journal of Neural Transmission, 115, 221-226. doi:10.1007/s00702-007-0813-6

Schoenmakers, T., Wiers, R. W., \& Field, M. (2008). Effects of a low dose of alcohol on cognitive biases and craving in heavy drinkers. Psychopharmacology, 197, 169-178. doi:10.1007/s00213-007-1023-5

Schuckit, M. A. (1994). Low level of response to alcohol as a predictor of future alcoholism. American Journal of Psychiatry, 151, 184-189.

Selzer, M. L., Vinokur, A., \& Van Rooijen, L. (1975). A self-administered Short Michigan Alcoholism Screening Test (SMAST). Journal of Studies on Alcohol, 36, 117-126.

Sobell, L. C., \& Sobell, M. B. (1992). Timeline follow-back: A technique for assessing self-reported alcohol consumption. In R. Litten \& J. Allen (Eds.), Measuring alcohol consumption: Psychosocial and biochemical methods (pp. 41-72). Totowa, NJ: Humana Press. doi:10.1007/978-14612-0357-5_3

Stacy, A. W., \& Wiers, R. W. (2010). Implicit cognitive and addiction: A tool for explaining paradoxical behavior. Annual Review of Clinical Psychology, 6, 551-575. doi:10.1146/annurev.clinpsy.121208.131444

Stanley, M. D., Poole, M. M., Stoops, W. W., \& Rush, C. R. (2011). Amphetamine self-administration in light and moderate drinkers. Alcoholism: Clinical and Experimental Research, 35, 443-453. doi:10.1111/ j.1530-0277.2010.01361.x

Ströhle, A., Stoy, M., Wrase, J., Schwarzer, S., Schlagenhauf, F., Huss, M., ... Heinz, A. (2008). Reward anticipation and outcomes in adult males with attention-deficit/hyperactivity disorder. Neuroimage, 39, 966-972. doi:10.1016/j.neuroimage.2007.09.044

Townshend, J. M., \& Duka, T. (2001). Attentional bias associated with alcohol cues: Differences between heavy and occasional social drinkers. Psychopharmacology, 157, 67-74. doi:10.1007/s002130100764

Weafer, J., Camarillo, D., Fillmore, M. T., Milich, R., \& Marczinski, C. A. (2008). Simulated driving performance of adults with ADHD: Comparisons with alcohol intoxication. Experimental and Clinical Psychopharmacology, 16, 251-263. doi:10.1037/1064-1297.16.3.251

Weafer, J., Fillmore, M. T., \& Milich, R. (2009). Increased sensitivity to the disinhibiting effects of alcohol in adults with ADHD. Experimental and Clinical Psychopharmacology, 17, 113-121. doi: $10.1037 / \mathrm{a} 0015418$

Weafer, J., \& Fillmore, M. T. (2008). Individual differences in acute alcohol impairment of inhibitory control predict ad libitum alcoho 
consumption. Psychopharmacology, 201, 315-324. doi:10.1007/ s00213-008-1284-7

Weafer, J., Milich, M., \& Fillmore, M. T. (2011). Behavioral components of impulsivity predict alcohol consumption in adults with ADHD and healthy controls. Drug and Alcohol Dependence, 113, 139-146. doi:10.1016/ j.drugalcdep.2010.07.027

Wechsler, H., Dowdall, G. W., Davenport, A., \& Rimm, E. B. (1995). A gender-specific measure of binge drinking among college students.
American Journal of Public Health, 85, 982-985. doi:10.2105/ AJPH.85.7.982

Received July 25, 2011

Revision received October 24, 2011

Accepted October 25, 2011 